\title{
MÉTODOS DE DIAGNÓSTICO E DIVERSIDADE DE INFECÇÕES POR Mycobacterium abscessus
}

\author{
MONTEIRO, JRS; SILVA, RF; LIMA, KVB e SOUSA, MS \\ Centro Universitário do Pára CESUPA; Instituto Evandro Chagas IEC Belém, PA e Universidade Federal do Pará \\ UFPA
}

Introdução: o Mycobacterium abscessus é responsável por vários tipos de infecções, tanto em pacientes imunocompetentes quanto em imunodeprimidos. O diagnóstico dessas infecções pode ser realizado mediante avaliação clínico-epidemiológica do paciente, auxiliada por métodos laboratoriais. A divulgação de novos métodos laboratoriais é importante no diagnóstico e na prevenção de novas infecções.

Objetivos: identificar os métodos laboratoriais de diagnóstico e de análise de diversidade das cepas de $M$. abscessus mais relatados no meio científico.

Método: o presente estudo realizou busca on-line de artigos completos, publicados em revistas científicas entre 1996 e 2006, que relataram infecções humanas causadas pelo M. abscessus. A busca identificou 39 publicações, as quais foram divididas em três grupos: 27 artigos de relatos de casos isolados (incluindo 15 infecções clínico-hospitalares), cinco artigos de revisão de casos e sete artigos de relatos de surtos e pseudosurtos.

Resultados: o levantamento das publicações nos permitiu verificar que os métodos diagnósticos mais relatados foram: baciloscopia, histopatológia, cultura, métodos cromatográficos (cromatografia gasosa - CG e cromatografia líquida de alta eficiência) e métodos moleculares, sendo os três primeiros os mais utilizados. Métodos de biologia molecular, tais como a Reação em Cadeia da Polimerase (PCR), a ERIC-PCR a RAPD e o seqüenciamento, foram relatados em cinco publicações, não apenas como técnicas auxiliares de diagnóstico, mas, também, na análise de diversidade e clonalidade entre infecções ocorridas em diferentes períodos. Cinco casos, previamente diagnosticados por baciloscopia como tuberculose, foram confirmados por cultura e PCR como infecções por M. abscessus.

Conclusão: identificamos que novas técnicas, tanto de diagnóstico rápido, como as que auxiliam na prevenção de novas infecções estão sendo utilizadas em relatos recentes de surtos e infecções hospitalares causadas pelo M. abscessus.

Fonte financiadora: FUNTEC/SECTAM, MS. rogeriomonteiro@globo.com. 